\title{
Prevention of liver cancer: basic and clinical aspects
}

\author{
Hisataka Moriwaki \\ Department of Internal Medicine \\ Gifu University School of Medicine \\ 40 Tsukasa-machi, Gifu 500-8705, Japan \\ Tel, 81-58-267-2843; Fax, 81-58-262-8484; \\ E-mail, hmori@cc.gifu-u.ac.jp
}

Accepted 12 September 2002

Abbreviations: AFP, $\alpha$-fetoprotein; HBV, hepatitis B virus; HCV, hepatitis $C$ virus; $R X R$, retinoid $X$ receptor

\begin{abstract}
Cancer prevention is a challenging project both in the basic and clinical medicine. In particular, prevention of liver cancer is the most urgent task in countries where the incidence of hepatitis virusrelated liver cancer is rising. As reviewed in this article, liver cancer is going to be the first cancer that will be actually prevented by primary and secondary interventions. Even the improvement of absolute survival of the patients can be expected by successful prevention, as already demonstrated in a few clinical trials. Thus, prevention of liver cancer is promising to provide not only costeffectiveness by morbidity reduction but also costbenefit by mortality improvement.
\end{abstract}

Keywords: liver cancer, cancer prevention, interferon, retinoid, apoptosis

\section{Introduction}

Liver cancer (hepatocellular carcinoma) is a major health care problem in eastern as well as western countries where hepatitis virus infection is endemic (Benhamiche et al., 1998; El-Serag and Mason, 1999; Makimoto and Higuchi, 1999; Edwards and Macdonald, 2000). Patients with viral liver cirrhosis have a high risk for liver cancer with an annual rate of carcinogenesis at approximately $7 \%$ (Nishiguchi et al., 1995; Oka et al., 1995; Imai et al., 1998; Kasahara et al., 1998; Ikeda et al., 1999; Yoshida et al., 1999). In particular, remnant cirrhotic liver after surgical resection or ablation of the initial liver cancer is exposed to a further higher risk of recurrent or second primary liver cancer (Muto et al., 1996; Tarao et al.,
1997; Ikeda et al., 2000; Kubo et al., 2001). The rate of this secondary carcinogenesis is estimated as $20-25 \%$ per year. However, the presence of such high-risk groups, in turn, makes the liver cancer a candidate target for cancer prevention project.

\section{Clinical characteristics of liver carcinogenesis}

Liver carcinogenesis is characterized by multistep carcinogenesis and by multicentric carcinogenesis. In a similar manner to other carcinomas, the liver cancer takes the course of multistep carcinogenesis (Figure 1), although responsible genomic changes for each step have not been elucidated yet. The whole course from initiation to the development of clinically detectable cancer is estimated to take 5-20 years. The carcinogenesis also steps up in parallel with the progression of chronic hepatitis that is represented by both the hepatic inflammation and fibrosis. This characteristic explains why the risk to develop liver cancer rises with the increasing grade of hepatitis (Imai et al., 1998; Kasahara et al., 1998; Ikeda et al., 1999; Yoshida et al., 1999). In addition, patients with liver cirrhosis around the age of 60 can be supposed to have premalignant or latent malignant (i.e., undetectable by imaging and other diagnostics) clones in the liver, when taking together the fact that the mean age of diagnosis of liver cancer is 65 years (Japanese Society for the Study of the Liver Cancer 2002).

Another characteristic of multicentric carcinogenesis is also expressed by the term "field cancerization" (Slaughter et al., 1953). In this context, the whole liver is exposed as a field to continuous carcinogenic insults such as hepatitis virus infection and alcohol toxicity, and develops multiple as well as independent transformed cell clones. Thus, the line of carcinogenesis as depicted in Figure 1, is supposed to go in multiple in the liver of such a patient. Hence, even if the first cancer is diagnosed and removed well in an early stage, the next clone essentially arises to form the second primary cancer.

In contrast to second primary tumors which arise from distinct clone from the initial cancer, recurrence is defined as the tumor which clone is same to the initial tumor. Thus, recurrence means actually the intrahepatic metastasis that could not be detected at the time of treatment for the initial tumor. Patients with liver cancer are also accompanied by frequent recurrences. While each one third of secondary liver cancer is defined as exact second primary tumor and recurrence, respectively, the remaining one third arises from undistinguishable clone (Chen et al., 2000). 


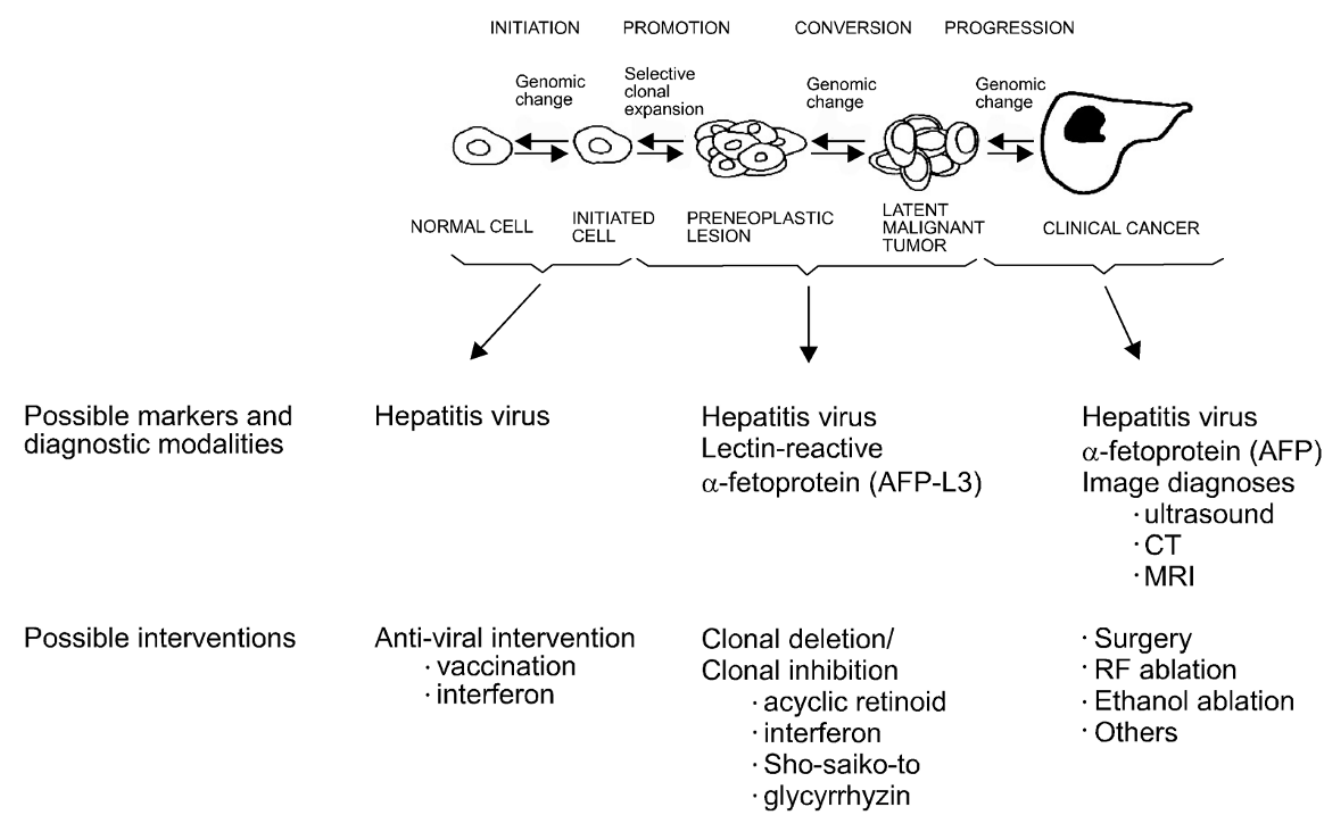

Figure 1. Schematic illustration of multistep liver carcinogenesis, possible clinical markers at each step, and candidate interventional modalities. $\mathrm{CT}$, X-ray computed tomography; MRI, magnetic resonance imaging; RF, radiofrequency.

The very high incidence of secondary liver cancer as mentioned above is brought about by such characteristic recurrence and multicentric carcinogenesis, and is actually responsible to the poor prognosis of the patients with liver cancer. The most recent follow-up study of 21,711 patients reports the 5-year survival rate as $52.3 \%$ (Japanese Society for the Study of the Liver Cancer 2002). In the present clinical practice, the early detection and treatment of secondary liver cancer is most important to provide the patients better outcome. In the future clinical practice, the prevention of secondary carcinogenesis will be the most urgent intervention for patients with liver cancer.

\section{Proposed hypotheses for the mechanism of liver carcinogenesis}

Chronic infection with hepatitis B virus (HBV) or hepatitis $C$ virus $(\mathrm{HCV})$ is widely recognized as the most important trigger of liver carcinogenesis both clinically (Benhamiche et al., 1998; El-Serag and Mason, 1999; Makimoto and Higuchi, 1999; Edwards and Macdonald, 2000) and experimentally (Kim et al., 1991; Moriya et al., 1998; Lerat et al., 2002). However, possible molecular events common after HBV and HCV infection have not been elucidated yet. An approach to find such events is analysis of chromosomal abnormalities in hepatoma tissues and subsequent identification of responsible genes on these chromosomes. Such suspected genes include p53, RB1, and $\beta$ - catenin (Huang and Marrero, 2002). Another approach is microarray comparison of gene expression profile between cancer tissues and surrounding noncancerous liver tissues (Graveel et al., 2001; Okabe et al., 2001; Tackels-Home et al., 2001). Several novel genes are proposed by these studies as responsible for the progress of multistep liver carcinogenesis.

A recent topic regarding the mechanism of liver carcinogenesis is impaired nuclear receptor function (Karpen, 2002). Typical abnormality in nuclear receptor function has been firstly described in acute promyelocytic leukemia, and is now a well established molecular target of differentiation induction therapy for this disease (Altucci and Gronemeyer, 2001). In liver carcinogenesis, interests have recently focused on retinoid X receptor (RXR) in clinical cases (NishiwakiMatsushima et al., 2001; Adachi et al., 2002) and in HCV-transgenic mouse model of liver carcinogenesis (Tsutsumi et al., 2002).

These studies on the mechanism of liver carcinogenesis seem to be encouraging to identify, in a near future, responsible genomic/molecular targets for novel therapeutic and interventional strategies.

\section{Classification of cancer prevention}

Cancer prevention is clinically classified into two categories of primary prevention and secondary prevention (Table 1) (Hong and Sporn, 1997). Primary prevention is further divided to two subcategories; (1) 
Table 1. Classification of clinical cancer prevention

1. Primary prevention
(1) Cancer prevention in general population
(2) Cancer prevention in subjects with risk factors
2. Secondary prevention
(1) Cancer prevention in patients with premalignant lesions
(2) Prevention against recurrence and second primary tumor

prevention in general population and (2) prevention targeting subjects with risk factors. Secondary cancer prevention also has two targets; (1) patients with premalignant lesions and (2) recurrent or second primary tumors in patients who received anti-cancer treatment for the initial tumor.

In the case of liver cancer, subcategory 1 of the primary prevention aims the intervention using public health measures such as universal vaccination against hepatitis virus in a general population in, for example, some townships, cities, or states. The simplest design for the subcategory 2 of the primary prevention is the removal of hepatitis virus from all virus carriers including healthy carriers and patients with chronic hepatitis.

Target patients with premalignant lesions in the secondary prevention indicates those with liver cirrhosis as described earlier. Prevention of recurrent or second primary tumor in the case of liver cancer aims the patients who received surgery, ablation, or other therapies for their initial liver cancers.

\section{Primary prevention of liver cancer}

The most fundamental strategy of primary prevention of liver cancer in general population is inhibition of hepatitis virus infection. Vertical (from mother to newborn) transmission of HBV can be avoided by injections of anti-HBV gamma-globulin and vaccination to the infants born from HBV-positive mothers. For example, this intervention actually started in the middle of 1970s in Japan, and reduced the HBV-positive rate in a cohort of blood donors from $2.3 \%$ in 1970 s to $0.9 \%$ in late 1990 s. However, another 25 years will be required to achieve the apparent reduction in HBVrelated adult liver cancer, since the average age of patients with type $B$ hepatoma is 50 s. An encouraging report is that, in countries where HBV-related childhood liver cancer is endemic, the effect of universal HBV vaccination has almost eradicated liver cancers in children (Chang et al., 1997).

Screening for HCV in donated blood started early in 1990s in developed countries to prevent HCV trans- mission via blood transfusion. Since HCV-related liver cancer develops approximately 20-25 years after bloodborn HCV infection, the incidence of HCV-positive liver cancer is anticipated to fall around year 20102015. However, a big problem of HCV transmission among intravenous drug-abusers remains still open in several countries.

Subjects with risk factors for liver cancer in the primary cancer prevention [subcategory 1-(2) in Table 1] include all asymptomatic as well as symptomatic carriers of hepatitis virus. Thus, prevention of liver cancer in patients with chronic viral hepatitis also belongs to this category. Currently, information regarding the effect of virus eradication from asymptomatic carriers on the subsequent risk of liver cancer is not available. In contrast, several reports indicate that interferon therapy to remove HCV from type C chronic hepatitis significantly reduced the risk of liver cancer (Nishiguchi et al., 1995; Imai et al., 1998; Kasahara et al., 1998; Ikeda et al., 1999; Yoshida et al., 1999). However, there are also criticisms against such cancer-preventive effect of interferon (Bruix et al., 2001).

\section{Secondary prevention of liver cancer}

In the secondary prevention of liver cancer, patients with premalignant lesions [subcategory 2-(1) in Table 1] respond to those with liver cirrhosis. Interferon therapy is reported to be effective on HCV-related liver carcinogenesis in cirrhotics (Nishiguchi et al., 1995), although its power is lower for liver cirrhosis than that for chronic hepatitis (Imai et al.,1998; Kasahara et al., 1998; Ikeda et al., 1999; Yoshida et al., 1999). Anti-inflammatory action of herbal medicine is also effective on liver carcinogenesis in non $B$ liver cirrhosis (Oka et al., 1995).

Successful prevention of recurrent and second primary liver cancer [2-(2) in Table 1] is reported using acyclic retinoid (Figure 2, upper panel) (Muto et al., 1996; 1999), glycyrrhizin (Tarao et al., 1997), and interferon (Ikeda et al., 2000; Kubo et al., 2001). In this context of secondary cancer prevention, the presence of transformed cell clone in the liver is already supposed. Hence, eradication of such clone is theoretically essential for the successful secondary cancer prevention. Thus, the category of this cancer prevention is also termed "clonal deletion", and seems nearer to the concept of therapy rather than that of prevention.

\section{Chemoprevention of liver cancer with retinoid}

Clonal deletion has been clinically demonstrated in a secondary prevention trial of liver cancer with acyclic retinoid (Moriwaki et al., 1997). Acyclic retinoid is a member of vitamin A analog, retinoids. Retinoids regu- 


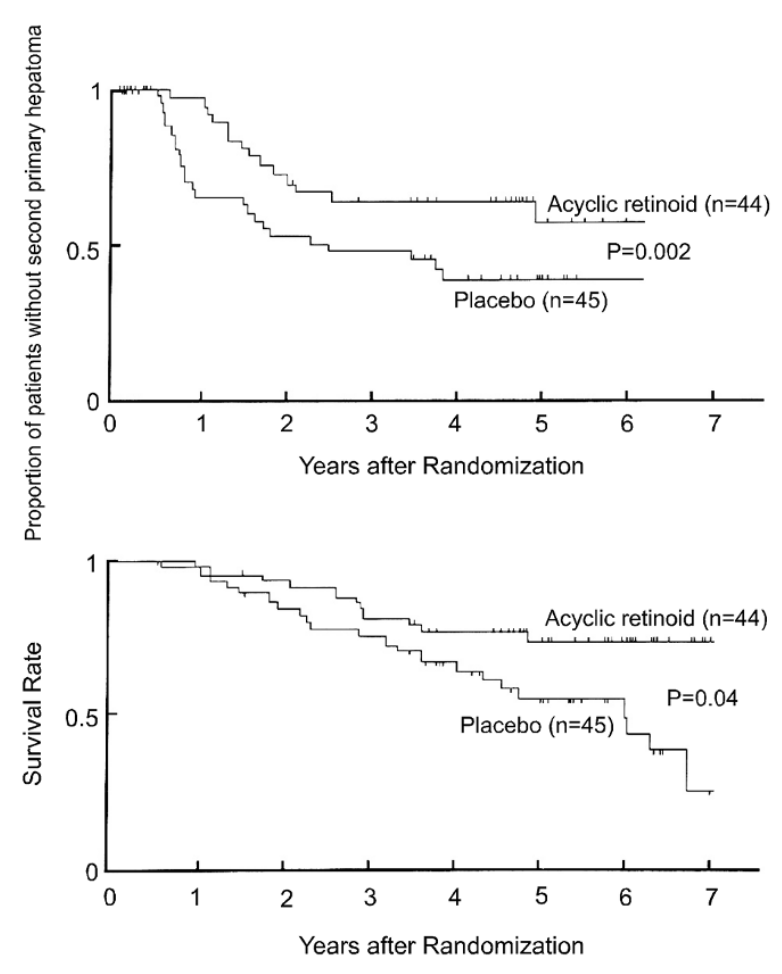

Figure 2. Effects of acyclic retinoid on the incidence of second primary tumors (upper panel) and survival (lower panel) (Muto et al., 1999 ) in patients with hepatocellular carcinoma after curative resection or ablation of the initial tumor. Acyclic retinoid or placebo was administered for the initial 1 year.

late cellular differentiation and morphogenesis through binding with nuclear steroid receptor superfamily proteins (Hong and Sporn, 1997; Altucci and Gronemeyer, 2001). This trail was performed using a multicenter, randomized controlled study design. Eightynine patients received curative resection or ablation of their primary hepatomas, and were followed-up for another 2 months to confirm that they were actually free of residual or recurrent hepatoma. They were then randomly assigned to either active group or placebo group. For the next 48 weeks, patients in the active group received oral acyclic retinoid with a dose of $600 \mathrm{mg} /$ day, while the placebo group took placebo capsules. Follow-up examination was done by ultrasound every 3 months and X-ray computed tomography every 6 months. Needle biopsy was carried out to diagnose histologically a possible lesion suspected of secondary hepatoma by US and CT imagings. Administration of the retinoid significantly reduced the incidence of secondary tumors after a median follow-up period of 38 months $(P=0.039)$ (Muto et al., 1996), and improved both the incidence $(P=0.002)$ and the survival $(P=0.04)$ after a median follow-up of 62 months (Figure 2) (Muto et al., 1999). Relative risk of the development of secondary hepa-
Table 2. Definition of cancer chemotherapy and cancer chemoprevention (Sporn and Newton, 1979)

Cancer chemotherapy: To kill cancer cells by blocking
key metabolic pathways
Cancer chemoprevention: To arrest or reverse
premalignant cells using physiological mechanism

toma was 0.31 (95\% confidence interval, 0.12-0.78) (Muto et al., 1996) in the retinoid group as compared to the placebo group, and that of death was 0.33 (0.11-0.79) (Muto et al., 1999).

In this study, serum $\alpha$-fetoprotein L3 isoform (AFPL3) has disappeared after 48 weeks administration of the retinoid in 4 of 5 patients who were positive for AFP-L3 at entry. In contrast, AFP-L3 rose after 48 weeks in all 4 patients of the placebo group with positive AFP-L3 at entry. Serum AFP-L3 is regarded to indicate the presence of transformed premalignant and latent malignant clones in the liver with chronic disease (Sato et al., 1993) and also in the remnant liver after surgical resection of hepatocellular carcinoma (Yamashita et al., 1996). Thus, the observations as described above suggest that the retinoid had deleted clones producing AFP-L3 (clonal deletion) (Moriwaki et al., 1997). Furthermore, serum AFP-L3 newly appeared in 8 patients in the placebo group who were negative at entry, whereas no patient turned to be AFP-L3 positive in the retinoid group. This observation indicates that the retinoid also inhibited the evolution of AFP-L3-producing clones (clonal inhibition) (Moriwaki et al., 1997).

In contrast to cancer prevention by interferon and glycirrhyzin with anti-viral or anti-inflammatory action, retinoid works directly on the carcinogenesis process through nuclear receptors. Such action of chemical compound is defined as cancer chemoprevention, and clearly differentiated from cancer chemotherapy (Table 2) (Sporn and Newton, 1979). In the action mechanism of acyclic retinoid, the reversal of premalignant clone is achieved by differentiation induction (Yamada et al., 1994), and arrest of the clone is done by apoptosis induction (Nakamura et al., 1995). A very recent study suggested that differentiation and apoptosis may be sequential, and that they might be linked by regulation of telomerase expression and activity (Figure 3) (Yasuda et al., 2002).

\section{Conclusion}

Cancer prevention is a challenging project both in the basic and clinical medicine. In particular, prevention 


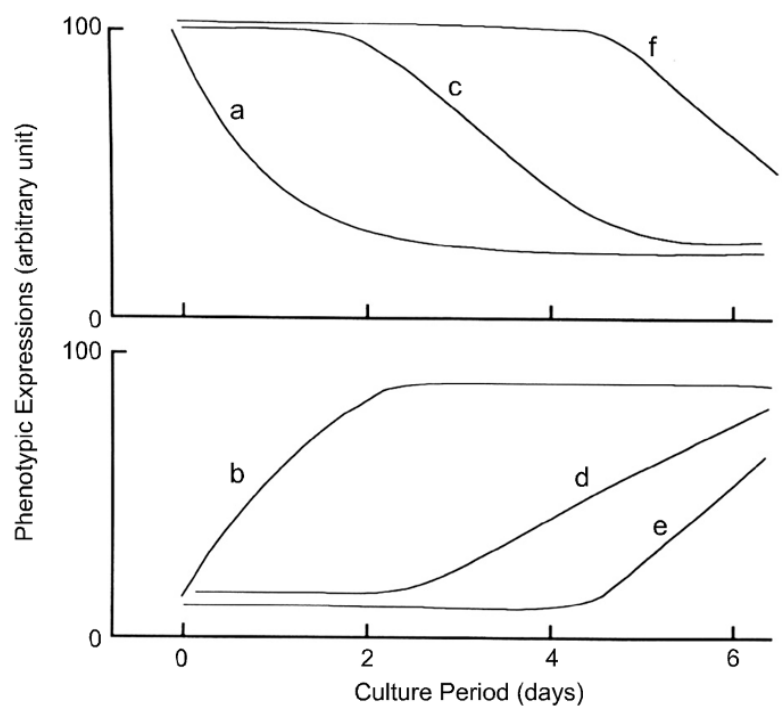

Figure 3. Action mechanism of acyclic retinoid to delete transformed clones. Human hepatoma-derived cell lines were treated in vitro with acyclic retinoid for the initial two days (modified from Yasuda 2002). a; down-regulation of alfa-fetoprotein mRNA expression and secretion, b; recovery of albumin mRNA expression and secretion, c; inhibition of telomerase reverse transcriptase (TERT) mRNA expression and telomerase activity, d; induction of caspase 8,9 , and 3 activities accompanied with mitochondrial membrane permeability transition and cytochrome $\mathrm{c}$ release, e; appearance of apoptotic cells, f; decrease in the number of viable cells (clonal deletion)

of liver cancer is the most urgent task in countries of eastern Asia, Europe, and also United States, where the incidence of hepatitis virus-related liver cancer is rising (Benhamiche et al., 1998; El-Serag and Mason, 1999; Makimoto and Higuchi, 1999). As reviewed in this article, liver cancer is going to be the first cancer that will be actually prevented by clinical interventions. Improvement of absolute survival of the patients can be expected by successful prevention of liver cancer with acyclic retinoid (Figure 2, lower panel) (Muto et al., 1999) and with interferon (Shiratori et al., 2000; Nishiguchi et al., 2001). Thus, prevention of liver cancer will provide not only costeffectiveness by morbidity reduction but also costbenefit by mortality improvement for both the patients and the society.

\section{Acknowledgements}

This study was supported in part by grants-in-aid from the Ministry of Education, Science, Sports, Technology and Culture of Japan (13220007 for scientific research on priority areas, and 13557048), and from the Ministry of Health, Labor and Welfare of Japan.

\section{References}

Adachi S, Okuno M, Matsushima-Nishiwaki R, Takano $\mathrm{Y}$, Kojima S, Friedman SL, Moriwaki H, Okano Y. Phosphorylation of retinoid $X$ receptor suppresses its ubiquitination in human hepatocellular carcinoma. Hepatology 2002;35:33240

Altucci L, Gronemeyer $\mathrm{H}$. The promise of retinoids to fight against cancer. Nat Rev Cancer 2001;1:181-93

Benhamiche AM, Faivre C, Minello A, Clinard F, Mitry E, Hillon $\mathrm{P}$, Faivre $\mathrm{J}$. Time trends and age-period-cohort effects on the incidence of primary liver cancer in a well-defined French population. J Hepatol 1998;29:802-6

Bruix J, Sherman M, Llovet JM, Beaugrand M, Lencioni R, Burroughs AK, Christensen E, Pagliaro L, Colombo M, Rodes J. Clinical management of hepatocellular carcinoma. Conclusions of the Barcelona-2000 EASL conference. European Association for the Study of the Liver. J Hepatol 2001; 35:421-30

Chang MH, Chen CJ, Lai MS, Hsu HM, Wu TC, Kong MS, Liang DC, Shau WY, Chen DS. Universal hepatitis B vaccination in Taiwan and the incidence of hepatocellular carcinoma in children. Taiwan Childhood Hepatoma Study Group. N Engl J Med 1997;336:1855-9

Chen YJ, Yeh SH, Chen JT, Wu CC, Hsu MT, Tsai SF, Chen $\mathrm{PJ}$, Lin $\mathrm{CH}$. Chromosomal changes and clonality relationship between primary and recurrent hepatocellular carcinoma. Gastroenterology 2000;119:431-40

Edwards JT, Macdonald GA. Hepatocellular carcinoma. Curr Opin Gastroenterol 2000;16:275-81

El-Serag HB, Mason AC. Rising incidence of hepatocellular carcinoma in the United States. N Engl J Med 1999;340: $745-50$

Graveel CR, Jatkoe T, Madore SJ, Holt AL, Farnham PJ. Expression profiling and identification of novel genes in hepatocellular carcinomas. Oncogene 2001;20:2704-12

Hong WK, Sporn MB. Recent advances in chemoprevention of cancer. Science 1997;278:1073-7

Huang MA, Marrero JA. Hepatocellular carcinoma. Curr Opin Gastroenterol 2002;18:345-50

Ikeda K, Arase Y, Saitoh S, Kobayashi M, Suzuki Y, Suzuki F, Tsubota A, Chayama K, Murashima N, Kumada H. Interferon beta prevents recurrence of hepatocellular carcinoma after complete resection or ablation of the primary tumor-A prospective randomized study of hepatitis $\mathrm{C}$ virus-related liver cancer. Hepatology 2000;32:228-32

Ikeda K, Saitoh S, Arase Y, Chayama K, Suzuki Y, Kobayashi M, Tsubota A, Nakamura I, Murashima N, Kumada H, Kawanishi M. Effect of interferon therapy on hepatocellular carcinogenesis in patients with chronic hepatitis type C: A long-term observation study of 1,643 patients using statistical bias correction with proportional hazard analysis. Hepatology 1999;29:1124-30

Imai Y, Kawata S, Tamura S, Yabuuchi I. Noda S, Inada M, Maeda Y, Shirai Y, Fukuzaki T, Kaji I, Ishikawa H, Matsuda Y, Nishikawa M, Seki K, Matsuzawa Y. Relation of interferon therapy and hepatocellular carcinoma in pa- 
tients with chronic hepatitis C. Ann Intern Med 1998;129: 94-9

Japanese Society for the Study of the Liver Cancer. The 15th report of national follow-up study of primary liver cancer, 1998-1999, 2002, 87, Japanese Society for the Study of the Liver Cancer, Kyoto

Karpen SJ. Nuclear receptor regulation of hepatic function. J Hepatol 2002;36:832-50

Kasahara A, Hayashi N, Mochizuki K, Takayanagi M, Yoshioka K, Kakumu S, lijima A, Urushihara A, Kiyosawa K, Okuda M, Hino K, Okita K. Risk factors for hepatocellular carcinoma and its incidence after interferon treatment in patients with chronic hepatitis C. Hepatology 1998;27:1394402

Kim CM, Koike K, Saito I, Miyamura T, Jay G. HBx gene of hepatitis $B$ virus induces liver cancer in transgenic mice. Nature 1991;351:317-20

Kubo S, Nishiguchi S, Hirohashi K, Tanaka H, Shuto T, Yamazaki O, Shiomi S, Tamori A, Oka H, Igawa S, Kuroki $\mathrm{T}$, Kinoshita $\mathrm{H}$. Effects of long-term postoperative interferonalpha therapy on intrahepatic recurrence after resection of hepatitis $\mathrm{C}$ virus-related hepatocellular carcinoma. A randomized, controlled trial. Ann Intern Med 2001;134:963-7

Lerat $\mathrm{H}$, Honda $M$, Beard MR, Loesch $K$, Sun J, Yang $Y$, Okuda M, Gosert R, Xiao SY, Weinman SA, Lemon SM. Steatosis and liver cancer in transgenic mice expressing the structural and nonstructural proteins of hepatitis $C$ virus. Gastroenterology 2002;122:352-65

Makimoto $\mathrm{K}$, Higuchi S. Alcohol consumption as a major risk factor for the rise in liver cancer mortality rates in Japanese men. Int J Epidemiol 1999;28:30-4

Matsushima-Nishiwaki R, Okuno M, Adachi S, Sano T, Akita $\mathrm{K}$, Moriwaki H, Friedman SL, Kojima S. Phosphorylation of retinoid $X$ receptor alpha at serine 260 impairs its metabolism and function in human hepatocellular carcinoma. Cancer Res 2001;61:7675-82

Moriwaki H, Yasuda I, Shiratori Y, Uematsu T, Okuno M, Muto $Y$. Deletion of serum lectin-reactive alpha-fetoprotein by acyclic retinoid: a potent biomarker in the chemoprevention of second primary hepatoma. Clin Cancer Res 1997;3: $727-31$

Moriya K, Fujie $H$, Shintani $\mathrm{Y}$, Yotsuyanagi $\mathrm{H}$, Tsutsumi T, Ishibashi K, Matsuura Y, Kimura S, Miyamura T, Koike K. The core protein of hepatitis $C$ virus induces hepatocellular carcinoma in transgenic mice. Nat Med 1998;4:1065-7

Muto $Y$, Moriwaki $H$, Ninomiya $M$, Adachi $S$, Saito $A$, Takasaki KT, Tanaka T, Tsurumi K, Okuno M, Tomita E, Nakamura T, Kojima T. Prevention of second primary tumors by an acyclic retinoid, polyprenoic acid, in patients with hepatocellular carcinoma. Hepatoma Prevention Study Group. N Engl J Med 1996;334:1561-7

Muto $\mathrm{Y}$, Moriwaki $\mathrm{H}$, Saito $\mathrm{A}$. Prevention of second primary tumors by an acyclic retinoid in patients with hepatocellular carcinoma. N Engl J Med 1999;340:1046-7

Nakamura N, Shidoji Y, Yamada Y, Hatakeyama H, Moriwaki $\mathrm{H}$, Muto $\mathrm{Y}$. Induction of apoptosis by acyclic retinoid in the human hepatoma-derived cell line, $\mathrm{HuH}-7$. Biochem
Biophys Res Commun 1995;207:382-8

Nishiguchi S, Kuroki T, Nakatani S, Morimoto H, Takeda T, Nakajima S, Shiomi S, Seki S, Kobayashi K, Otani S. Randomised trial of effects of interferon-alpha on incidence of hepatocellular carcinoma in chronic active hepatitis $\mathrm{C}$ with cirrhosis. Lancet 1995;346:1051-5

Nishiguchi S, Shiomi S, Nakatani S, Takeda T, Fukuda K, Tamori A, Habu D, Tanaka T. Prevention of hepatocellular carcinoma in patients with chronic active hepatitis $\mathrm{C}$ and cirrhosis. Lancet 2001;357:196-7

Oka H, Yamamoto S, Kuroki T, Harihara S, Marumo T, Kim SR, Monna T, Kobayashi K, Tango T. Prospective study of chemoprevention of hepatocellular carcinoma with Shosaiko-to (TJ-9). Cancer 1995;76:743-9

Okabe H, Satoh S, Kato T, Kitahara O, Yanagawa R, Yamaoka Y, Tsunoda T, Furukawa Y, Nakamura Y. Genomewide analysis of gene expression in human hepatocellular carcinomas using cDNA microarray: identification of genes involved in viral carcinogenesis and tumor progression. Cancer Res 2001;61:2129-37

Sato $Y$, Nakata K, Kato Y, Shima M, Ishii N, Koji T, Taketa $\mathrm{K}$, Endo $\mathrm{Y}$, Nagataki S. Early recognition of hepatocellular carcinoma based on altered profiles of alpha-fetoprotein. $\mathrm{N}$ Engl J Med 1993;328:1802-6

Shiratori Y, Imazeki F, Moriyama M, Yano M, Arakawa Y, Yokosuka O, Kuroki T, Nishiguchi S, Sata M, Yamada G, Fujiyama S, Yoshida H, Omata, M. Histologic improvement of fibrosis in patients with hepatitis $\mathrm{C}$ who have sustained response to interferon therapy. Ann Intern Med 2000;132: $517-24$

Slaughter DP, Southwick HW, Smejkal W. "Field cancerization" in oral stratified squamous epithelium: Clinical implication of multicentric origin. Cancer 1953;6:963-8

Sporn MB, Newton DL. Chemoprevention of cancer with retinoids. Fed Proc 1979;38:2528-34

Tackels-Horne D, Goodman MD, Williams AJ, Wilson DJ, Eskandari T, Vogt LM, Boland JF, Scherf U, Vockley JG. Identification of differentially expressed genes in hepatocellular carcinoma and metastatic liver tumors by oligonucleotide expression profiling. Cancer 2001;92:395-405

Tarao K, Takemiya S, Tamai S, Sugimasa Y, Ohkawa S, Akaike M, Tanabe $H$, Shimizu A, Yoshida M, Kakita A. Relationship between the recurrence of hepatocellular carcinoma (HCC) and serum alanine aminotransferase levels in hepatectomized patients with hepatitis $\mathrm{C}$ virus-associated cirrhosis and HCC. Cancer 1997;79:688-94

Tsutsumi T, Suzuki T, Shimoike T, Suzuki R, Moriya K, Shintani $Y$, Fujie $H$, Matsuura $Y$, Koike $K$, Miyamura $T$. Interaction of hepatitis $C$ virus core protein with retinoid $X$ receptor alpha modulates its transcriptional activity. Hepatology 2002;35:937-46

Yamada Y, Shidoji Y, Fukutomi Y, Ishikawa T, Kaneko T, Nakagama H, Imawari M, Moriwaki H, Muto Y. Positive and negative regulations of albumin gene expression by retinoids in human hepatoma cell lines. Mol Carcinog 1994;10:151-8

Yamashita F, Tanaka M, Satomura S, Tanikawa K. Prognostic significance of Lens culinaris agglutinin A-reactive alpha- 
fetoprotein in small hepatocellular carcinomas. Gastroenterology 1996;111:996-1001

Yasuda I, Shiratori Y, Adachi S, Obora A, Takemura M, Okuno M, Shidoji Y, Seishima M, Muto Y, Moriwaki $H$. Acyclic retinoid induces partial differentiation, down-regulates telomerase reverse transcriptase mRNA expression and telomerase activity, and induces apoptosis in human hepatomaderived cell lines. J Hepatol 2002;36:660-71
Yoshida H, Shiratori Y, Moriyama M, Arakawa Y, Ide T, Sata M, Inoue O, Yano M, Tanaka M, Fujiyama S, Nishiguchi S, Kuroki T, Imazeki F, Yokosuka O, Kinoyama S, Yamada G, Omata M. Interferon therapy reduces the risk for hepatocellular carcinoma: national surveillance program of cirrhotic and noncirrhotic patients with chronic hepatitis $C$ in Japan. Ann Intern Med 1999;131:174-181 